Research Article

\title{
Spatial Spillover Effect of Financial Flexibility on Investment in China's Convention and Exhibition Listed Companies
}

\author{
Xiaoqun Liu $\mathbb{D},{ }^{1}$ Liuchun Yu $\mathbb{D},{ }^{1}$ Yuchen Zhang $\mathbb{D}{ }^{1}$ and Youcong Chao $\mathbb{D}^{2}$ \\ ${ }^{1}$ School of Economics, Hainan University, Haikou, Hainan 570228, China \\ ${ }^{2}$ School of Business, Central South University, Changsha, Hunan 410083, China \\ Correspondence should be addressed to Youcong Chao; chaoyoucong87@163.com
}

Received 12 July 2020; Revised 14 September 2020; Accepted 24 September 2020; Published 19 October 2020

Academic Editor: Chuangxia Huang

Copyright (C) 2020 Xiaoqun Liu et al. This is an open access article distributed under the Creative Commons Attribution License, which permits unrestricted use, distribution, and reproduction in any medium, provided the original work is properly cited.

Financial flexibility is an important research issue in corporate finance. This paper utilizes the Spatial Durbin Model (SDM) to analyze the impact of financial flexibility on the investment of Convention and Exhibition companies listed on the New Third Board from 2014 to 2016. The empirical results show the following. Firstly, the greater the financial flexibility, the more investment the firm will make. Secondly, the enhancement in financial flexibility would lead to an increase in investment of companies in the Convention and Exhibition industry in the local provinces, indicating that the financial flexibility has a significant positive intraregional spatial spillover effect on investment. On the other hand, financial flexibility has spatial spillover effects, and its rise will reduce the investment in other provinces, which could be explained by the competition effect between enterprises. Overall, we have further elucidated the role of different levels of financial flexibility on the investment of the Convention and Exhibition listed enterprises from the spatial dimension, thereby enriching the existing research on corporate financial flexibility and corporate value to some certain extent.

\section{Introduction}

According to the "China Convention and Exhibition industry's capital market development report in 2016," released by China Convention and Exhibition Society in the end of 2017, China's Convention and Exhibition industry has experienced a rapid development with its growth rate reaching 11.1 percent, which is far higher than the GDP growth rate of 6.7 percent, and also higher than the growth rate of $7.8 \%$ of the added value of other service industries. On the other hand, there are fewer Convention and Exhibition enterprises above the designated size in our country, scattered with low-degree concentration, and it is vulnerable to be affected by the overall macroeconomic fluctuations. While the Convention and Exhibition industry is in urgent need of financial support from capital market, it is especially important for its listed enterprises to make rational use of capital and seize favorable investment opportunities for sustainable development. In theory of corporate finance, the key to effective use of funds lies in the financial flexibility of enterprises, which is closely related to the investment of enterprises. In order to enhance enterprise value, it is of strategic significance to quantify the impact of financial flexibility of Convention and Exhibition listed enterprises on investment by using an appropriate econometric model.

Financial flexibility refers to enterprises' capability to obtain or transfer financial resources in time in order to take precautions against or take great advantage of uncertain events, grasp valuable investment opportunities, and ultimately realize its optimal value [1-3]. In other words, financial flexibility represents an enterprise's ability to respond to unexpected shocks or investment opportunities of uncertainty at quite low cost [4]. When confronted with an unfavorable economic environment, the amount of debt financing determines the probability of enterprises coping with the crisis and avoiding bankruptcy risks, while the capital structure of low debt means good financial flexibility. Overseas researchers mainly concentrated on the following two aspects. First is the impact of financial flexibility on enterprise performance, value, and investment [5-7]. For 
example, Gamba and Triantis [5] developed a model that endogenizes dynamic financing, investment, and cash retention/payout policies in order to analyze the effect of financial flexibility on firm value. Using the 2007 financial crisis as a natural experiment, Ferrando et al. [7] found that a higher degree of financial flexibility allows firms to reduce the negative impact of liquidity of shocks on investment and thus support the hypothesis that the financial flexibility improves companies' capability to undertake future investment. The second one is the application of specific financial decision-making [7, 8]; specifically, Almeida et al. [8] studied a model in which future financing constraints lead firms to have a preference for investments with shorter payback periods, investments with less risk, and investments that utilize more pledgeable assets, which indirectly revealed that the financial flexibility would affect the financial investment policy. In China, the previous researches focus on the following three points. First is the theory and practice of the relationship between financial flexibility and enterprise investment behavior, including the effects of financial flexibility posed on the performance of microenterprises under uncertain environment $[9,10]$, dividend policy [11], and investment decision-making choices [12]. Second is research on the relationship between financial flexibility and enterprise financing behavior [13-15]. The last one is introducing certain constraints into the original topic, such as bank credit granting [16], environmental uncertainty and enterprise characteristics [17], political connections of private enterprises [18], and overconfidence of managers [19], making the results more sufficient and credible.

Specifically, as for the financial flexibility and investment, researchers found that the path of the impact of financial flexibility on investment efficiency is complex: for example, the financial flexibility can be measured by cash flexibility and debt flexibility [20]; besides, investment contains underinvestment and overinvestment [12-14]. Moreover, financing constraint is an adjustment variable for the relationship between financial flexibility and insufficient investment of enterprises [14,21,22]; in addition, the enhanced effect of the financial flexibility on the investment of the company in future is profoundly affected by the effectiveness of corporate governance [23].

Enlightened by the above literature review, our motivation is attempting to use a quantitative method to investigate the exact relationship between financial flexibility and investment in Convention and Exhibition industry. The possible contributions of our paper may lie in the following two dimensions. First, the scope of the research will be carried out at the industry level. At present, instead of taking the new three-board tourism enterprises as the main research object, most of the researches in China are concentrated in A-share listed enterprises [24-31]. Furthermore, in terms of research methods, quantitative analysis is employed by using the spatial panel econometric model from the spatial dimension. As we all know, quantitative analysis has become a necessary yet crucial method for almost all kinds of research areas [32-37]. As far as we know, there is no literature using this econometric empirical model to investigate the relationship between financial flexibility and investment in Convention and Exhibition enterprises. As an emerging industry, the Convention and Exhibition industry has its unique nature, thus, exploring the internal relationship between financial flexibility and investment in this industry is beneficial for the Convention and Exhibition industry, which is relatively small in strength until now, not only to grasp investment opportunities and achieve stable development in an uncertain economy, but also to enrich the research results of the overall capital market in this field.

The remainder of the paper is organized as follows. Section 2 describes the theoretical mechanism and methods and specifies the spatial econometric model setting. Empirical analysis and results are presented in Section 3, and we make conclusions in Section 4.

\section{Theories and Methods}

2.1. Theoretical Mechanism. This paper utilizes the space panel econometric model to study the relationship between financial flexibility and investment of Convention and Exhibition listed enterprises. In the empirical analysis, the province where the enterprise is located is indicated as its spatial location.

Before analyzing the spatial spillover mechanism of corporate financial flexibility on corporate investment, we must first figure out how corporate financial flexibility directly affects intraregional corporate investment, as the spatial spillover effect is the extension of the direct effect to a certain extent. Financial flexibility is one of the important indicators that affect the investment level of enterprises [21]. In an uncertain market environment, by maintaining favorable financial flexibility through sufficient cash flow holding and low leverage rate, enterprises can not only smoothly survive on fierce external environmental threats, but also, more importantly, obtain external financing support easily, so as to seize future investment opportunities and improve corporate value.

Krugman [38] considered that spillover effects are never confined within the initial spillover site by either geographical or administrative boundaries. In general, financial flexibility may produce a spatial spillover effect through the following channel: a pure knowledge technology spillover effect-in order to achieve the corporate value by seizing investment opportunity, the company will emulate the investment behavior of enterprises in the same industry by drawing lessons from their components' excellent financial flexibility plan and formulating their own financing scheme.

\subsection{Spatial Econometric Model Setting}

2.2.1. Benchmark Model Settings and Descriptions. Due to the lack of available data, while the quantitative method has become a trend in economy related issues [39-45], most of the researches belong to qualitative analysis in Convention and Exhibition industry area, and we try to utilize the following spatial econometric model to investigate the exact relationship between financial flexibility and investment. 
The first step of studying the existence of the spatial spillover effect is correctly setting the spatial econometric model. Three spatial panel models are mainly adopted in empirical research: the spatial lag model, the spatial error model, and the SDM. Based on the specific purpose and theoretical mechanism of the study, this paper attempts to explore the spatial impact of financial flexibility on corporate investment with the SDM. In addition, combined with Richardson's model and Yu's [21] research, as well as the availability to the variables, our model is as follows:

$$
\text { Invest }_{i t}=\rho W_{i t} \text { Invest }_{i t}+\theta W_{i t} \mathrm{FF}_{i t}+\eta \mathrm{Size}_{i t}+\varphi \mathrm{Tan}_{i t}+\kappa \mathrm{CF}_{i t}+\mu_{i}+\delta_{t}+\varepsilon_{i t}, \quad \varepsilon_{i t} \sim N\left(0, \sigma^{2}\right) \text {, }
$$

where subscript $i$ denotes a Convention and Exhibition company and $t$ denotes a semiannual, Invest ${ }_{i t}$ is the dependent variable, representing the ratio of the cash paid for the purchase on fixed assets, intangible assets, and other long-term assets in $t$ year minus the net cash paid for the disposed fixed assets, intangible assets, and other long-term assets, as well as their depreciation and amortization in $t$ year, to the average total assets, and $W$ is the exogenous space weight matrix, $\mathrm{FF}_{i t}$ is the independent variable, an abbreviation for financial flexibility, $W_{i t}$ Invest $_{i t}$ specifies the weight matrix for the spatial-autoregressive term, and $\rho$ is the spatial correlation coefficient indicating the degree of influence between adjacent variables, $W_{i t} \mathrm{FF}_{i t}$ specifies the weight matrix for the spatially lagged regressor, and $\theta$ is its spatial coefficient. Size $_{i t}$, $\mathrm{Tan}_{i t}$, and $\mathrm{CF}_{i t}$ are control variables, representing the ratio of fixed asset to total assets and cash flow, respectively, $\mu_{i}$ and $\delta_{t}$ represent the city individual effect and time fixed effect, respectively, and $\varepsilon_{i t}$ is random error term. Given the distribution function, Anselin [46] pointed out that a consistent unbiased estimate can be obtained by using maximum likelihood estimation, and the spatial panel maximum likelihood estimation is used in this paper. In fact, the "endogeneity problem" in this case has to do with simultaneous equations, and formula (1) actually can be interpreted as a "typical" equation of a simultaneous equation model with as many equations as there are cities $(i=1,2, \ldots, n)$.

In addition, we would apply the Hausman test to decide whether the spatial econometric model with fixed effect or with the random effect model would be employed.

2.2.2. Measurement of Direct and Indirect Effects. In a spatial setting, the effect of an explanatory variable change in a particular unit affects not only that unit but also its neighbors. By applying the concept of partial differential method in mathematics, Lesage and Pace [47] propose to measure the direct and indirect effects between adjacent regions. Furthermore, Elhorst [48] applies this approach to the direct and indirect effects measurement in SDM, taking into account the spatial correlation information of the dependent variables and the independent variables.

According to these researchers' ideas, the existence of an intraregional spillover effect is not related to the estimated coefficient of explanatory variables $(\beta)$, so we should pay attention to whether the direct effect of the estimation of explanatory variables is significant. Also, to test for the existence of a spatial spillover effect, we should concentrate on whether the indirect effect of explanatory variables is significant, and not either the spatial autocorrelation coefficient $(\rho)$ or the spatial lag coefficient of explanatory variables $(\theta)$. Assume that the general matrix expression of the SDM model is as shown in the following:

$$
Y_{i t}=\rho W Y_{i t}+\beta X_{i t}+\theta W X_{i t}+\mu_{i}+\delta_{t}+\varepsilon_{i t},
$$

where $Y_{i t}$ is the explained vector and $X_{i t}$ represents an explanatory variable vector. $\rho$ is the spatial autocorrelation coefficient, $W$ is the exogenous space weight matrix, and $\rho W$ represents $\rho$ multiple $W$; the use of $\rho W$ is calculating the direct and indirect effect, which possesses no economic meaning, however, while $W Y_{i t}$ also signifies $W$ multiple $Y_{i t}$; it has a true economic meaning; that is, $W Y_{i t}$ is a new explanatory variable.

It is modified as shown in the following:

$$
Y_{i t}=(1-\rho W)^{-1}\left(\beta X_{i t}+\theta W X_{i t}\right)+(1-\rho W)^{-1} \mu_{i}+(1-\rho W)^{-1} \delta_{t}+(1-\rho W)^{-1} \varepsilon_{i t} \text {, }
$$

where the interpretations of $\rho$ and $\theta$ are the same as (2), and in the process of the model construction, if $\theta=0$, then the
SDM degrades into the SLM, and if $\theta+\rho \beta=0$, it degrades into SEM; otherwise, it still SDM. 
Taking a partial derivative of formula (3) to the $k$-th explanatory variable, a partial differential matrix is obtained, as shown in the following:

$$
\left[\frac{\partial Y}{\partial X_{i t}} \times \frac{\partial Y}{\partial X_{N t}}\right]=\left[\begin{array}{c}
\frac{\partial Y_{1}}{\partial X_{1 t}} \times \frac{\partial Y_{1}}{\partial X_{N t}} \\
\vdots \\
\frac{\partial Y_{N}}{\partial X_{1 t}} \times \frac{\partial Y_{N}}{\partial X_{N t}}
\end{array}\right]=(I-\rho W)^{-1}\left[\begin{array}{cccc}
\beta_{t} & w_{12} \delta_{t} & \cdots & w_{1 N} \delta_{t} \\
w_{21} \delta_{t} & \beta_{t} & \cdots & w_{2 N} \delta_{t} \\
\vdots & \vdots & \ddots & \vdots \\
w_{N 1} \delta_{t} & w_{N 2} \delta_{t} & \cdots & \beta_{t}
\end{array}\right]
$$

where the average value of the elements on the main diagonal of the matrix is defined as the direct influence of the $k$-th explanatory variable on the explained variable in the region; the average value of elements other than diagonal lines is defined as the indirect effect of the explanatory variable affected by other regions.

2.2.3. Setting of Spatial Weight Matrix W. Regional agglomeration characteristics, namely, spatial autocorrelation, indicate whether there are significant spatial spillover and mutual imitation effects in the variables. We calculated Moran's $I$ index to test for the existence of the spatial correlation [47]. Moran's I index is defined as follows.

$X$ is variable, including both the explained and explanatory variables, and $W$ represents an adjacent order matrix with $n \times n$ spaces; the key issue becomes how to choose a reasonable $W$. Either the contiguity based spatial weight matrix (W1) or distance based spatial weights (W2) are widely used. In this paper, we use the former, and we find that the empirical results do not change when the alternative is applied. $W 1$ is expressed as follows:

$$
W_{i j}= \begin{cases}1, & \text { regions } i \text { and } j \text { are neighboring regions, } \\ 0, & \text { regions } i \text { and } j \text { are not neighboring regions, }\end{cases}
$$

In this paper, Moran's I index of all explanatory variables and dependent variables is calculated, with the aim of judging whether the spatially lagged term of the variables should be taken as an additional explanatory variable. At the same time, a statistical test for the significance of Moran's $I$ index needs to be conducted; this is usually achieved by a $Z$ test of normal distribution.

\subsection{Specific Variables}

2.3.1. Dependent Variable. The explanatory variable of this article is the enterprise financial flexibility, which is quantified as the sum of cash flexibility and debt financing flexibility by using the method of multi-index combination [23, 49]. In fact, Zeng et al. [49] summarized that the measurement of financial flexibility is as follows at home and abroad: single index measurement, multi-index combination measurement, and multi-index synthesis measurement. The first one assesses the degree of financial flexibility by a single index, while the second one is combining multiple indexes at the same time. Thus, in this paper, the financial flexibility is defined as follows:

financial flexibility $=$ financial debt ratio + cash asset ratio,

where

$$
\begin{aligned}
\text { financial debt ratio } & =\frac{\left(\begin{array}{r}
\text { total current liability }+ \text { short }- \text { term loan }+ \text { noncurrent liabilities due within one year } \\
+ \text { transactional financial liabilities }+ \text { transactional financial liabilities }
\end{array}\right)}{\text { total liability }}, \\
\text { cash asset ratio } & =\frac{\text { ending balance of cash and cash equivalents }}{\text { total assets }} .
\end{aligned}
$$


2.3.2. Key Explanatory Variable. This paper focuses on the spatial impact of corporate financial flexibility on corporate investment; thus, the core explanatory variable is corporate investment. Corporate investment is calculated as the cash paid for the purchase on fixed assets, intangible assets, and other long-term assets in $t$ year minus the net cash paid for the disposed fixed assets, intangible assets, and other longterm assets, as well as their depreciation and amortization in $t$ year divided the book value of total assets at end of period; this is,

$$
\text { investment }=\frac{\left(\begin{array}{c}
\text { the cash paid for the purchase on fixed assets, intangible assets, and other long }- \text { term assets } \\
- \text { the net cash paid for the disposed fixed assets, intangible assets, and other long }- \text { term assets }
\end{array}\right)}{\text { book value of total assests at end of period }} .
$$

2.3.3. Control Variables. Enlightened by the extant researches on financial flexibility and investment of other industries, like Yu [21] and Dai and Ren [23], which verified that the corporate size, cash flow, and the ratio of fixed asset to total assets significantly determined the total expenditure of the corporate investment; this paper also takes these variables as crucial control variables. The definitions of all the control variables are as follows:

size: natural logarithm of the ending total assets,

$$
\begin{aligned}
& \qquad \text { cash flow }=\frac{\text { net cash flow from operating activities }}{\text { ending total assets }}, \\
& \text { ratio of physical assets }=\frac{\text { fixed asset }}{\text { total assets }}
\end{aligned}
$$

\section{Empirical Analysis}

3.1. Data and Descriptive Statistics. Considering the influence of changes in corporate accounting standards and according to the classification of "Activity Content," this paper selected companies listed in the national small- and medium-sized enterprise share transfer system from 2014 to 2016 with the industry attributes of "business service industry" and "sports" as research samples; the detailed reasons are as the development of China's convention and exhibition industry is still in the primary stage, strictly speaking, there are no mature listed ones in China. Meanwhile, there is no authoritative definition for the convention and exhibition enterprises, and this paper adopts the concepts of "activities" to identify the sample selection, specifically, the companies which aim to organize activities, provide information services, organize offline activities or provide online and offline integrated marketing services, and gather specific people on specific occasions in the mode of project operation; more importantly, the organization and operation services provided that have third-party attributes, emphasizing the participation of "people" and meeting the financial requirements of 2014 to 2016 , will be selected as our sample. Undeniably, the deficiency of this paper is the limited data selection and acquisition, which may lead to the error of the research results to a certain extent. At the same time, the paper removed the samples under the following conditions. First is excluding enterprises in the media industry of the business service industry that only focus on advertising production and film and television production, leasing, media, printing, and so on. The characteristic of such enterprises is that their main business is only one procedure in the whole planning and operation process. Second, enterprises that are in the business of providing service for real estate and tourist attractions to promote sales are not included; the reason is that such planning and operation only provide warm-up and promotion services for its real main business income, which is not the main business itself. Third, eliminating enterprises lacking public released financial information in 2014 to 2016.

In all, the samples spanned from 2014 to 2016 depend on the availability of the data, primarily originating from the CSMAR database. After satisfying the above constraints, 12 sample companies were obtained. Table 1 reports the mean, the standard deviation, the maximum, and the minimum of the variables. As shown, the mean of corporate investment and financial flexibility are 0.05 and 0.46, respectively, whereas, in Chen et al.'s [15] and in Yu's [21] papers, the mean of these two variables are 0.04 and 0.07 and 0.05 and -0.05 , respectively, indicating that there are obvious differences in the financial flexibility of different industries. 
TABLE 1: Descriptive statistics of the variables.

\begin{tabular}{lccccc}
\hline Variable & Obs & Mean & Std. Dev. & Min & Max \\
\hline Invest & 72 & 0.0494 & 0.0895 & -0.0230 & 0.3860 \\
FF & 72 & 0.4620 & 0.2490 & 0.0379 & 0.9760 \\
ln size & 72 & 7.7700 & 0.4480 & 0.7860 & 8.7040 \\
Tan & 72 & 0.0749 & 0.1020 & -2.0058 & 0.5770 \\
CF & 72 & $2.52 E+06$ & $1.86 E+07$ & 07 & $1.07 E+08$ \\
\hline
\end{tabular}

TABle 2: Moran's I of FF and Invest from 2014 to 2016 semiannually.

\begin{tabular}{lcccccc}
\hline FF & Moran's $I$ & $Z$-statistic & $P$ value & Invest & Moran's $I$ & $Z$-statistic \\
\hline 201412 & 0.744 & 2.653 & 0.001 & 201412 & 0.309 & 4.389 \\
201506 & 0.684 & 2.753 & 0.002 & 201506 & 0.322 & 4.546 \\
201512 & 0.726 & 2.543 & 0.003 & 201512 & 0.735 & 3.650 \\
201606 & 0.343 & 2.617 & 0.008 & 201606 & 0.873 & 3.005 \\
\hline
\end{tabular}
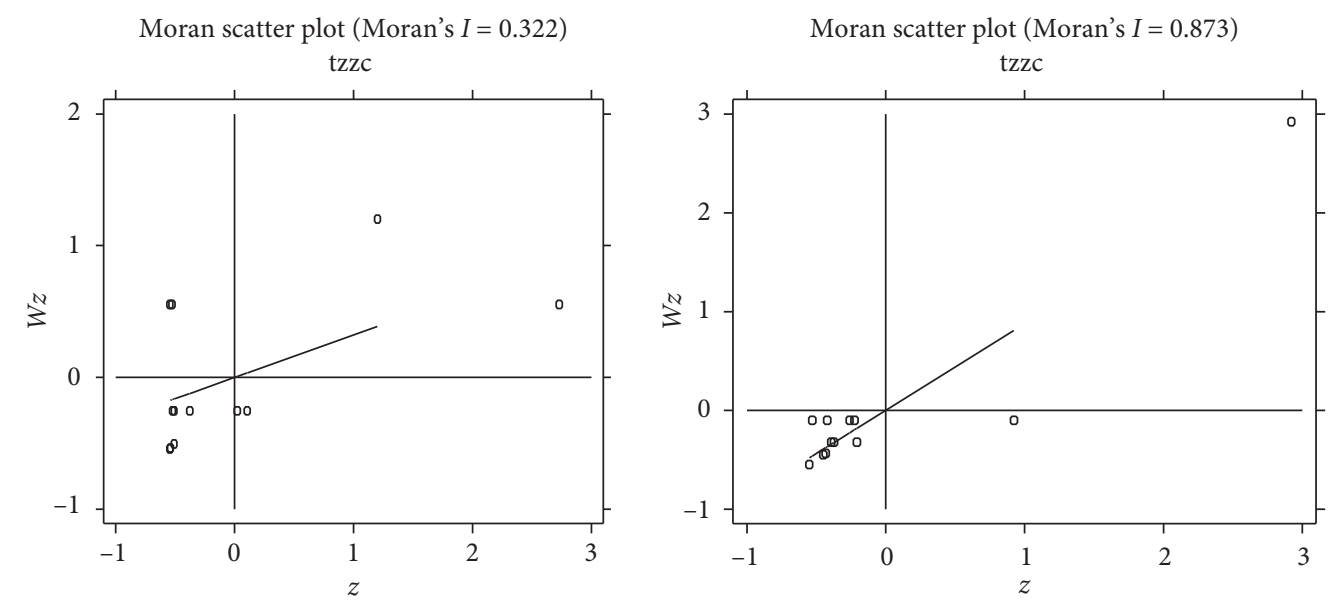

FIgURE 1: Scatter plot of Moran's I for investment (tzzc) at Q2 2015 and Q2 2016.
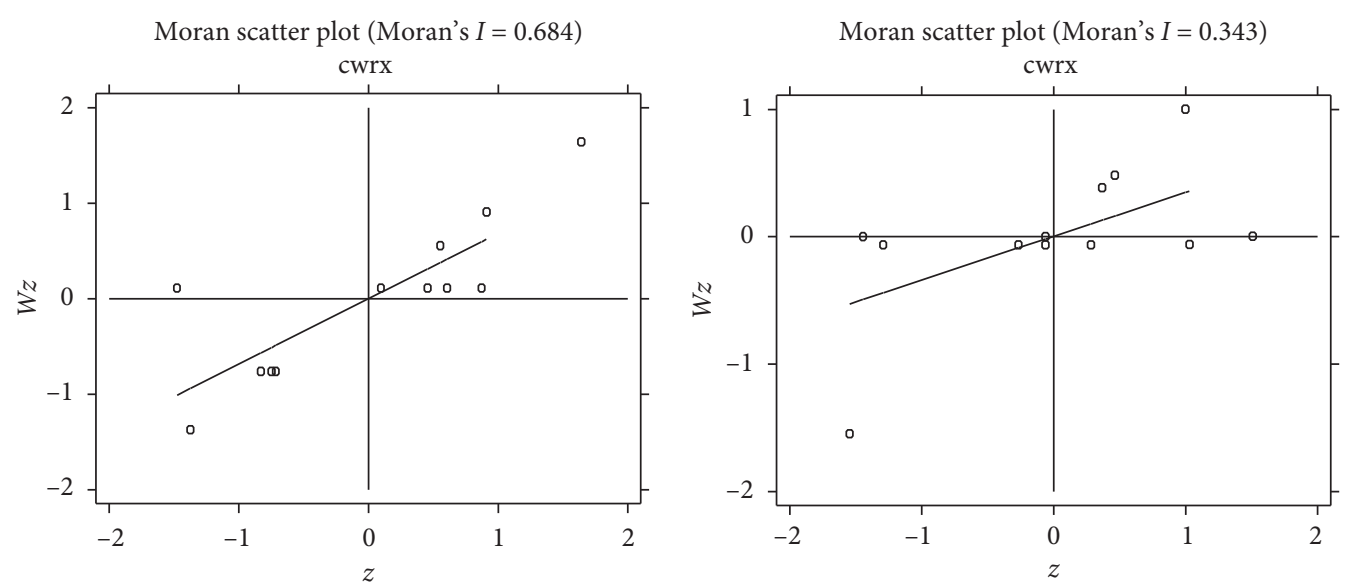

FIgure 2: Scatter plot of Moran's I for financial flexibility (cwrx) at Q2 2015 and Q2 2016.

3.2. Empirical Results. The explanatory variables' Moran's I indexes are calculated by GeoDa software. Moran's I index is within $(-1,1)$; its zero value indicates that there is no spatial correlation, while greater than zero and less than zero represent positive and negative spatial correlations, respectively. Table 2 reports Moran's I of FF and Invest 
TABLE 3: SDM regression results for financial flexibility and investment.

\begin{tabular}{lcccc}
\hline Invest & Coef. & Std. Err. & $z$ & $P>|z|$ \\
\hline Main & & & & \\
Invest. L1. & $-0.2460^{* * *}$ & 0.0690 & -3.56 & 0.0000 \\
Winvest L1. & $0.3330^{* * *}$ & 0.0778 & 4.28 & 0.0000 \\
FF & $\mathbf{0 . 0 3 7 7 ^ { * }}$ & $\mathbf{0 . 0 2 0 4}$ & $\mathbf{1 . 8 4}$ & $\mathbf{0 . 0 6 5}$ \\
ln size & $0.0854^{* * *}$ & 0.0211 & 4.05 & 0.0000 \\
Tan & 0.1470 & 0.1160 & 1.27 & 0.2050 \\
CF & 0.0000 & $2.16 E-10$ & 0.04 & 0.9640 \\
\hline Wx & & & & \\
Invest & 19338 & - & - & - \\
FF & -0.0226 & 0.0529 & -0.43 & 0.669 \\
\hline Spatial & & & & \\
Rho & $19337^{* * *}$ & 0.0358 & 540000 & 0.0000 \\
$R^{2}$ & 0.857 & & & \\
\hline
\end{tabular}

Note. Main is explanatory variables without the Durbin terms, $W x$ represents the weight matrix for the spatially lagged dependent and independent variables, Spatial means the existence of spatial effect, Coef. is the coefficient of the explanatory variable, $Z$ is the critical value of the $Z$-test, and $R^{2}$ signifies the fitness of the whole model. All these symbols are the same for all tables. ${ }^{*},{ }^{* *}$, and ${ }^{* * *}$ represent $10 \%, 5 \%$, and $1 \%$ significance levels, respectively.

from 2014 to 2016 semiannual and the $Z$-statistic and $P$ value, and it can be found that Moran's $I$ indexes of the corporate financial flexibility are significantly greater than zero to certain extent, indicating an obvious positively spatial autocorrelation exists. Therefore, it would be appropriate to employ the SDM to conduct our empirical analysis.

To further investigate the characteristics of the autocorrelation of corporate financial flexibility and investment, Moran's I scatter plots are generated to depict local spatial autocorrelation features in Figures 1 and 2, and the sample period is at the second quarter of 2015 (Q2 2014) and 2016 (Q2 2016), whose Moran's I for investment are 0.322 and 0.873 , respectively, and Moran's $I$ for financial investment are 0.684 and 0.343 , respectively. The four quadrants of Moran's I scatter plots reflect the spatial connection of the region to its neighboring regions. The data points in quadrant I to quadrant 4 represent the HH type, the LH type, the LL type, and the HL type, respectively. The first and third quadrants reflect the positive spatial autocorrelation. It can seem that, for most of the enterprises, the $\mathrm{HH}$ and the LL
TABLE 4: SDM regression results of direct and indirect effects of financial flexibility on investment.

\begin{tabular}{|c|c|c|c|c|}
\hline Invest & Coef. & Std. Err. & $z$ & $P>|z|$ \\
\hline \multicolumn{5}{|l|}{ SR Direct } \\
\hline $\mathrm{FF}$ & $0.0199^{* *}$ & 0.0098 & 2.03 & 0.0420 \\
\hline lnsize & $0.0424^{* * *}$ & 0.0106 & 4.02 & 0.0000 \\
\hline Tan & 0.0714 & 0.0574 & 1.25 & 0.2130 \\
\hline CF & 0.0000 & 0.0000 & 0.01 & 0.9880 \\
\hline Invest & $0.5000^{* * *}$ & $9.30 E-07$ & 540000 & 0.0000 \\
\hline \multicolumn{5}{|l|}{ SR Indirect } \\
\hline $\mathrm{FF}$ & $-0.0199^{* *}$ & 0.0098 & -2.03 & 0.0420 \\
\hline lnsize & $-0.0424^{* * *}$ & 0.0106 & -4.02 & 0.0000 \\
\hline Tan & -0.0714 & 0.0574 & -1.25 & 0.2130 \\
\hline CF & 0.0000 & 0.0000 & -0.01 & 0.9880 \\
\hline Invest & $0.5000^{* * *}$ & 0.0000 & 540000 & 0.0000 \\
\hline \multicolumn{5}{|l|}{ LR Direct } \\
\hline FF & $0.0160^{* *}$ & 0.0079 & 2.03 & 0.0420 \\
\hline lnsize & $0.0341^{* * *}$ & 0.0085 & 4.02 & 0.0000 \\
\hline Tan & 0.0573 & 0.0461 & 1.25 & 0.2130 \\
\hline CF & 0.0000 & 0.0000 & 0.01 & 0.9880 \\
\hline Invest & $0.5000^{* * *}$ & 0.0000 & 540000 & 0.0000 \\
\hline \multicolumn{5}{|l|}{ LR Indirect } \\
\hline $\mathrm{FF}$ & $-0.0160^{* * *}$ & 0.0079 & -2.03 & 0.0420 \\
\hline lnsize & $-0.0341^{* * *}$ & 0.0085 & -4.02 & 0.0000 \\
\hline Tan & -0.0573 & 0.0460 & -1.25 & 0.2130 \\
\hline $\mathrm{CF}$ & 0.0000 & 0.0000 & -0.01 & 0.9880 \\
\hline Invest & $0.5000^{* * *}$ & 0.0000 & 540000 & 0.0000 \\
\hline
\end{tabular}

Note. LR_Direct and LR_Indirect are the long-run direct effect and indirect effect of the variables. ${ }^{*},{ }^{* *}$, and ${ }^{* * *}$ represent $10 \%, 5 \%$, and $1 \%$ significance levels, respectively.

types account for the variables of corporate financial flexibility and investment. Moreover, as time goes by, an increasing number of provinces transfer to the first quadrant (HH type) of each variable, indicating that the spatial differentiation characteristics are obvious.

According to Moran's I value of investment, the full dynamic SDM model in Table 3 is applied for analysis; that is to say, the paper used the SDM model with both the time and space lagged dependent variable and space lagged independent variable. And in part of robustness test, the SDM model with spatial lagged terms will be used:

$$
\text { Invest }_{i t}=\beta \text { Invest }_{i t-1}+\rho W_{i t} \text { Invest }_{i t}+\rho^{\prime} W_{i t} \text { Invest }_{i t-1}+\beta \mathrm{FF}_{i t}+\theta W_{i t} \mathrm{FF}_{i t}+\theta^{\prime} W_{i t} \mathrm{FF}_{i t-1}+\eta \operatorname{Size}_{i t}+\varphi \mathrm{Tan}_{i t}+\kappa \mathrm{CF}+\mu_{i}+\delta_{t}+\varepsilon_{i t} \text {. }
$$

The empirical regression of the model in Table 3 preliminarily manifests that the corporate financial flexibility (denoted by "FF" in "Main" of the Table) is statistically positive, indicating the higher degree of the financial flexibility of the enterprises, the more investment expenditure. At the same time, the "rho" of "Spatial" in the table is obviously significant, which represents the feasibility of adding time and space lagged spillover effects of dependent variable. In all, Table 3 shows that we could apply the SDM model to quantitatively investigate the effect of financial flexibility on investment in the Convention and Exhibition industry. 
TABLE 5: SDM_dlag regression results for financial flexibility on investment.

\begin{tabular}{lcccc}
\hline Invest & Coef. & Std. Err. & $z$ & $P>|z|$ \\
\hline Main & & & & \\
Winvest L1. & 0.0590 & 0.0474 & 1.25 & 0.2130 \\
FF & $0.0533^{*}$ & 0.0286 & 1.87 & 0.0620 \\
lnsize & $0.0638^{* * *}$ & 0.0217 & 2.94 & 0.0030 \\
Tan & 0.0713 & 0.0931 & 0.77 & 0.4440 \\
CF & 0.0000 & 0.0000 & 0.01 & 0.9950 \\
\hline$W x$ & & & & \\
Invest & 12707 & - & - & - \\
FF & -0.0477 & 0.0668 & -0.71 & 0.4750 \\
\hline Spatial & & & & \\
Rho & 12706 & 0.0306 & 410000 & 0.0000 \\
Variance & & & & \\
Sigma2 & $0.0008^{* *}$ & 0.0004 & 2.02 & 0.0430 \\
$R^{2}$ & 0.872 & & & \\
\hline
\end{tabular}

${ }^{*},{ }^{* *}$, and ${ }^{* * *}$ represent $10 \%, 5 \%$, and $1 \%$ significance levels, respectively.

Meanwhile, in a spatial setting, Lesage and Pace [47] propose to measure the direct and indirect effects between adjacent regions due to the effect of an explanatory variable change in a particular unit would affect not only that unit but also its neighbors. Thus, based on Table 3 , Table 4 shows the empirical results of direct and indirect effects of financial flexibility on enterprise investment expenditures.

The empirical results of Table 4 manifest that the shortterm and long-term direct effects of financial flexibility are significantly positive, indicating that the enhancement in financial flexibility would lead to an increase in investment of companies in the Convention and Exhibition industry in the local province; that is to say, financial flexibility has a significant positive intraregional spatial spillover effect on investment. On the other hand, the short-term and longterm indirect effects of financial flexibility are significantly negative, implying that financial flexibility has spatial spillover effects, and its rise will reduce the investment in other cities, which could be explained by the competition effect between enterprises.

Convention and exhibition industry is an emerging service industry. One of the most outstanding features for this industry is "the clustering effect," which means that the regional competitiveness of convention and exhibition industry is very fierce, as shown by the empirical results in Table 4: financial flexibility has spatial spillover effects, and its rise will reduce the investment in other cities,
TABLE 6: SDM_dlag regression results of direct and indirect effects of financial flexibility on investment.

\begin{tabular}{|c|c|c|c|c|}
\hline Invest & Coef. & Std. Err. & $z$ & $P>|z|$ \\
\hline \multicolumn{5}{|l|}{ SR Direct } \\
\hline $\mathrm{FF}$ & $0.0259^{*}$ & 0.0141 & 1.83 & 0.0670 \\
\hline lnsize & $0.0328^{* * *}$ & 0.0107 & 3.06 & 0.0020 \\
\hline Tan & 0.0364 & 0.0472 & 0.77 & 0.4410 \\
\hline CF & 0.0000 & 0.00175 & 0.01 & 0.9940 \\
\hline Invest & $0.5000^{* * *}$ & $1.64 E-06$ & 310000 & 0.0000 \\
\hline \multicolumn{5}{|l|}{ SR Indirect } \\
\hline $\mathrm{FF}$ & $-0.0259^{*}$ & 0.0141 & -1.83 & 0.0670 \\
\hline lnsize & $-0.0328^{* * *}$ & 0.0107 & -3.06 & 0.0020 \\
\hline Tan & -0.0364 & 0.0472 & -0.77 & 0.4410 \\
\hline CF & 0.0000 & 0.00175 & -0.01 & 0.9940 \\
\hline Invest & $0.5000^{* * *}$ & $1.64 E-06$ & 310000 & 0.0000 \\
\hline \multicolumn{5}{|l|}{ LR Direct } \\
\hline $\mathrm{FF}$ & $0.0259^{*}$ & 0.0141 & 1.83 & 0.0670 \\
\hline lnsize & $0.03288^{* * *}$ & 0.0107 & 3.06 & 0.0020 \\
\hline Tan & 0.0364 & 0.0472 & 0.77 & 0.4410 \\
\hline $\mathrm{CF}$ & $1.35 E-05$ & 0.00175 & 0.01 & 0.9940 \\
\hline Invest & $0.5000^{* * *}$ & $1.64 E-06$ & 310000 & 0.0000 \\
\hline \multicolumn{5}{|l|}{ LR Indirect } \\
\hline $\mathrm{FF}$ & $0.0259^{*}$ & 0.0141 & 1.83 & 0.0670 \\
\hline lnsize & $0.0328^{* * *}$ & 0.0107 & 3.06 & 0.0020 \\
\hline Tan & 0.0364 & 0.0472 & 0.77 & 0.4410 \\
\hline CF & 0.0000 & 0.00175 & 0.01 & 0.9940 \\
\hline Invest & $0.5000^{* * *}$ & $1.64 E-06$ & 310000 & 0.0000 \\
\hline
\end{tabular}

${ }^{*},{ }^{* *}$, and ${ }^{* * *}$ represent $10 \%, 5 \%$, and $1 \%$ significance levels, respectively.

which could be explained by the competition effect between enterprises. As we can see, in reality, most of the Convention and Exhibition enterprises are mainly distributed in Beijing, Shanghai, Guangzhou, Dalian, Shenzhen, Xiamen, and other economically developed areas. According to the survey data, Beijing is the first province to hold the most exhibitions in China, followed by Shanghai and Guangdong. From the perspective of exhibition revenue, Guangdong, Beijing, and Shanghai occupy a monopoly position, accounting for nearly $90 \%$ of the national exhibition revenue.

3.3. Robustness Tests. The paper applies the SDM model with the space lagged dependent variable and independent variable (abbreviated as SDM_dlag) to conduct the robustness test. The model is as follows:

$$
\text { Invest }_{i t}=\rho W_{i t} \text { Invest }_{i t}+\rho^{\prime} W_{i t} \text { Invest }_{i t-1}+\beta \mathrm{FF}_{i t}+\theta W_{i t} \mathrm{FF}_{i t}+\theta^{\prime} W_{i t} \mathrm{FF}_{i t-1}+\eta \text { Size }_{i t}+\varphi \operatorname{Tan}_{i t}+\kappa \mathrm{CF}+\mu_{i}+\delta_{t}+\varepsilon_{i t} \text {, }
$$

Tables 5 and 6 examine the impact of financial flexibility on investment with SDM_dlag.
As can be seen from Tables 5 and 6, when considering the space lagged effect only, the significance of financial flexibility has not changed greatly. Moreover, while both 
long-run direct effect and short-term effect of financial flexibility are significantly positive, the indirect effects are statistically negative. Therefore, it signifies that robustness test analysis is consistent with that of the main part.

\section{Conclusion}

This paper utilizes the Spatial Durbin Model to examine the spatial spillover effect of financial flexibility on investment from a specific industry perspective, 12 Convention and Exhibition enterprises listed on the New Third Board. This is quite distinct from previous studies that have focused on A-share listed companies from the Main Board Security Market and using common panel econometric models. The empirical results show that financial flexibility in Convention and Exhibition companies has spatial spillover effects, and its rise will reduce the investment in other provinces, which could be explained by the competition effect between enterprises.

These empirical evidences from an emerging industry are complementary to the existing literature on the topic predominantly resting on the US and Europe market and the Main Board Security Market in China. However, due to the limited listed time of Convention and Exhibition enterprises, the length of data is limited. In the future, we will track over the data and make reexamination.

\section{Data Availability}

All relevant data are available from GitHub: https:/github. com/LiuxiaoqunFinancialResearchGroup/financial_flexibility.

\section{Additional Points}

Considering the influence of changes in corporate accounting standards, and according to the classification of "Activity Content," this paper selected companies listed in the national small and medium-sized enterprise share transfer system from 2014 to 2016 with the industry attributes of "business service industry" and "sports" as research samples, and removed the samples under the following conditions. First is excluding enterprises in the media industry of the business service industry that only focus on advertising production and film and television production, leasing, media, printing, and so on. The characteristic of such enterprises is that their main business is only one procedure in the whole planning and operation process. Second, enterprises that are in the business of providing service for real estate and tourist attractions to promote sales are not included; the reason is that such planning and operation only provide warm-up and promotion services for its real main business income, which is not the main business itself. Thirdly, eliminating enterprises lacking public released financial information in 2014 to 2016. In all, the samples spanned from 2014 to 2016 depending on the availability of the data, primarily originating from the CSMAR database. After satisfying the above constraints, 12 sample companies were obtained.

\section{Conflicts of Interest}

The authors declare no conflicts of interest with respect to the research, authorship, and/or publication of this article.

\section{Acknowledgments}

This research was supported by the National Natural Science Foundation of Hainan Province $(\mathrm{CN})$, under Grant no. 718MS032; the National Natural Science Foundation of China, under Grant nos. 71761010 and 72063005; the Foundation of Hainan Educational Committee, under Grant no. Hnky 2018-9.

\section{References}

[1] J. R. Graham and C. R. Harvey, "The theory and practice of corporate finance: evidence from the field," Journal of Financial Economics, vol. 60, no. 2-3, pp. 187-243, 2001.

[2] FASB, "Preliminary views on financial statement presentation," FASB, Norwalk, CT, USA, Discussion Paper, 2008.

[3] H. He and L. DeAngelo, "Capital structure, payout policy, and financial flexibility," SSRN Working Paper No. FBE 02-06, Marshall School of Business, Los Angeles, CA, USAMarshall School of Business, 2009 .

[4] C.-A. Ma and Y. Jin, "What drives the relationship between financial flexibility and firm performance: investment scale or investment efficiency? evidence from China," Emerging Markets Finance and Trade, vol. 52, no. 9, pp. 2043-2055, 2016.

[5] A. Gamba and A. Triantis, "The value of financial flexibility," The Journal of Finance, vol. 63, no. 5, pp. 2263-2296, 2008.

[6] M.-T. Marchica and R. Mura, "Financial flexibility, investment ability, and firm value: evidence from firms with spare debt capacity," Financial Management, vol. 39, no. 4, pp. 1339-1365, 2010.

[7] A. Ferrando, M.-T. Marchica, and R. Mura, "Financial flexibility and investment ability across the euro area and the UK," European Financial Management, vol. 23, no. 1, pp. 87-126, 2017.

[8] H. Almeida, M. Campello, and M. S. Weisbach, "Corporate financial and investment policies when future financing is not frictionless," Journal of Corporate Finance, vol. 17, no. 3, pp. 675-693, 2011.

[9] W. Q. Yuan, H. J. Wang, and X. Huang, "Financial flexibility, corporate investment and operating performance: empirical analysis based on monetary tightening," Review of Investment Studies in China, vol. 35, pp. 57-73, 2016.

[10] Y. Gu and Q. L. Zhou, "Policy uncertainty, value of financial flexibility and dynamic adjustment of capital structure," The Journal of World Economy, vol. 6, pp. 102-126, 2018.

[11] F. Wang and J. Ni, "Financing constraints, financial flexibility and dividend-policy choice," Economist, vol. 4, pp. 79-87, 2016.

[12] M. H. Tian and L. Ye, "A study on the impact path of financial flexibility on inefficient investment," Collected Essays on Financial and Economics, vol. 3, pp. 57-65, 2015. 
[13] M. Wang, X. J. Sha, and M. H. Tian, "Financial flexibility, the level of corporate governance and over-investment," Economic Survey, vol. 33, pp. 102-106, 2016.

[14] M. Wang, N. Xu, and M. H. Tian, "Financing constraints, financial flexibility and corporate under-investment," $R e$ search on Financial and Economic Issues, vol. 9, pp. 85-93, 2016.

[15] Y. Chen and X. Yang, "The influence of financial flexible reserves on the company's capital investment: from the perspective of capital cost anchoring," Macroeconomics, vol. 4, pp. 140-150, 2018.

[16] T. Ju and L. H. Guo, "Bank credit, financial flexibility and over-investment," Studies of International Finance, vol. 6, pp. 53-64, 2015.

[17] M. A. Liu and X. H. Xiang, "Environment uncertainty, corporate characteristics and financial flexibility," Macroeconomics, vol. 4, pp. 127-134, 2014.

[18] M. Wang and Z. X. Liu, "Research on substitution effect of private enterprises' political connection on financial flexibility reserves," Journal of Management Science, vol. 29, no. 5, pp. 116-133, 2016.

[19] C. A. Ma and C. Yi, "A study of the effects of managerial overconfidence on financial flexibility," Accounting Research, vol. 7, pp. 75-81, 2017.

[20] Q. Q. Yin and J. X. Hu, "Financial flexibility, free cash flow and under-investment: evidence from Chinese listed companies," Journal of Hehai University (Philosophy and Social Sciences), vol. 18, pp. 49-57, 2016.

[21] S. Y. Yu, "Financing constraints, financial flexibility and corporate investment: theory analysis and empirical test," Research on Financial and Economic Issues, vol. 8, pp. 65-72, 2016.

[22] W. W. Zhang, "Financing constraints, financial flexibility, corporate operating performance," Research on Financial and Economic Issues, vol. 6, pp. 102-109, 2016.

[23] X. F. Dai and S. K. Ren, "Corporate governance and financial flexibility and investment: based on the fixed effect model," South China Finance, vol. 9, pp. 48-54, 2016.

[24] F. Karim, S. Chauhan, and J. Dhar, "On the comparative analysis of linear and nonlinear business cycle model: effect on system dynamics, economy and policy making in general," Quantitative Finance and Economics, vol. 4, no. 1, pp. 172203, 2020

[25] L. Mathys, "Valuing tradeability in exponential Lévy models," Quantitative Finance and Economics, vol. 4, no. 3, pp. 459$488,2020$.

[26] F. Wen, L. Xu, G. Ouyang, and G. Kou, "Retail investor attention and stock price crash risk: evidence from China," International Review of Financial Analysis, vol. 65, 2019.

[27] F. Wen, N. Wu, and X. Gong, "China's carbon emissions trading and stock returns," Energy Economics, vol. 86, p. $104627,2020$.

[28] Z. Li, M. Tian, G. Ouyang, and F. Wen, "Relationship between investor sentiment and earnings news in high- and lowsentiment periods," International Journal of Finance and Economics, pp. 1-18. In press, 2020.

[29] Z. Dai, H. Zhou, F. Wen, and S. He, "Efficient predictability of stock return volatility: the role of stock market implied volatility," The North American Journal of Economics and Finance, vol. 52, p. 101174, 2020.

[30] C. Huang, S. Wen, M. Li, F. Wen, and X. Yang, “An empirical evaluation of the influential nodes for stock market networks: Chinese A shares case," Finance Research Letters, 2020, In press.
[31] J. Cao and F. Wen, "The impact of the cross-shareholding network on extreme price movements: evidence from China," Journal of Risk, vol. 22, no. 2, pp. 79-102, 2019.

[32] P. Liu, H. Yang, H. Wu, M. Ju, and F. E. Alsaadi, "Some maclaurin symmetric mean aggregation operators based on cloud model and their application to decision-making," International Journal of Information Technology \& Decision Making, vol. 18, no. 3, pp. 981-1007, 2019.

[33] H. Li, X. Zhu, J. Chen, and F. Jiang, "Environmental regulations, environmental governance efficiency and the green transformation of China's iron and steel enterprises," Ecological Economics, vol. 165, p. 106397, 2019.

[34] J. Chen, X. Zhu, and H. Li, "The pass-through effects of oil price shocks on China's inflation: a time-varying analysis," Energy Economics, vol. 86, p. 104695, 2020.

[35] F. Zhu, F. Jin, H. Wu, and F. Wen, "The impact of oil price changes on stock returns of new energy industry in China: a firm-level analysis," Physica A: Statistical Mechanics and Its Applications, vol. 532, p. 121878, 2019.

[36] Z. He, F. Zhou, X. Xia, F. Wen, and Y. Huang, "Interaction between oil price and investor sentiment: nonlinear causality, time- varying influence, and asymmetric effect," Emerging Markets Finance and Trade, vol. 55, no. 12, pp. 2756-2773, 2019.

[37] Z. He, J. Chen, F. Zhou, and F. Wen, "Oil price uncertainty and the risk-return relation in stock markets: evidence from oil-importing and oil-exporting countries," International Journal of Finance and Economics, pp. 1-19. In press, 2020.

[38] P. Krugman, "Increasing returns and economic geography," Journal of Political Economy, vol. 99, no. 3, pp. 483-499, 1991.

[39] Q. Peng, F. Wen, and X. Gong, "Time-dependent intrinsic correlation analysis of crude oil and the US dollar based on CEEMDAN," International Journal of Finance and Economics, pp. 1-15. In press, 2020.

[40] J. Chen and X. Zhu, "The effects of different types of oil price shocks on industrial PPI: evidence from 36 sub-industries in China," Emerging Markets Finance and Trade, pp. 1-24. In press, 2019.

[41] X. Chen, Y. Li, J. Xiao, and F. Wen, "Oil shocks, competition, and corporate investment: evidence from China," Energy Economics, vol. 89, 2020.

[42] Z. Ye, C. Hu, L. He, G. Ouyang, and F. Wen, "The dynamic time-frequency relationship between international oil prices and investor sentiment in China: a wavelet coherence analysis," Energy Journal, vol. 41, no. 1, 2020.

[43] X. Yang, S. Wen, Z. Liu, C. Li, and C. Huang, "Dynamic properties of foreign exchange complex network," Mathematics, vol. 7, no. 9, p. 832, 2019.

[44] X. Yang, X. Zhao, X. Gong, X. Yang, and C. Huang, "Systemic importance of China's financial institutions: a jump volatility spillover network review," Entropy, vol. 22, no. 5, p. 588, 2020.

[45] X. Yang, S. Wen, X. Zhao, and C. Huang, "Systemic importance of financial institutions: a complex network perspective," Physica A: Statistical Mechanics and Its Applications, vol. 5451, 2020.

[46] L. Anselin, Spatial Econometrics: Methods and Models, Springer, Dordrecht, Netherland, 1988.

[47] J. Lesage and R. K. Pace, Introduction to Spatial Econometric, CRC Press, Boca Raton, FL, USA, 2009.

[48] J. P. Elhorst, Spatial Econometrics: From Cross-Sectional Data to Spatial Panels, Springer, Berlin, 2013.

[49] A. M. Zeng, C. Zhang, and C. H. Zhu, "Latest research progress in western financial flexibility theory," Journal of Business Economics, vol. 10, pp. 43-54, 2014. 